Orlando R. Hung FRCPC, Laurel Comeau BSc, Mark R. Riley BSc, Stephen Tan BSc, Sara Whynot MLT, Michael Mezei PhD*

\section{Comparative topical anaesthesia of EMLA and liposome-encapsulated tetracaine}

Background: The eutectic mixture of local anaesthetics (EMLA) provides effective topical anaesthesia after a minimum of 60 to $90 \mathrm{~min}$ application. Since liposome-encapsulated tetracaine (LET) can provide rapid dermal penetration. the goal of this study was to compare the local anaesthetic effects of EMLA and LET in human volunteers after $60 \mathrm{~min}$ application.

Methods: After obtaining institutional approval and informed consent, healthy volunteers were recruited in a double blind, crossover, randomized trial. The study creams $(0.5 \mathrm{ml}$ EMLA and $0.5 \mathrm{ml}$ LET $5 \%)$ were applied randomly to opposite arms for $60 \mathrm{~min}$. The discomfort of iv catheterization was assessed using a visual analogue pain score (VAS). Cutaneous side effects of the creams were recorded.

Results: Sixty-one subjects were studied. Twenty-one were excluded because of technical difficulties. Forty subjects completed the study and were included in the data analysis. The mean ( \pm SD) VAS was lower for LET than for EMLA $(10.9 \pm 9.0 \mathrm{~mm}$ vs $22.7 \pm 17.1 \mathrm{~mm}, P<0.001)$. Enythema secondary to vasodilatation occurred more frequent in the LET group than in the EMLA group ( 33 vs 3.P<0.001). One subject with a history of atopy developed a rash at the LET application site.

Conclusion: Liposome-encapsulated tetracaine can provide a more effective topical anaesthesia than EMLA for intravenous catheterization after $60 \mathrm{~min}$ application. Clinical evaluations are necessary to determine the efficacy and safety of LET in providing topical anaesthesia for various invasive percutaneous procedures in other patient populations.

Objectif : Le mélange eutectique d'anesthésique local (EMLA) appliqué pendant 60 à 90 minutes procure une anesthésie topique efficace. On sait que tétracaine encapsulée dans les liposomes (LET) pénètre le derme rapidement. Cette étude a été entreprise pour comparer les effets anesthésiques locaux de l'EMLA et du LET chez des volontaires humains après 60 min d'application.

Méthodes : Après obtention de l'approbation des instances appropriées et du consentement éclairé, des volontaires ont été recrutés dans une étude aléatoire croisée à double insu. Les crèmes (EMLA $0.5 \mathrm{ml}$ et LET 5\% 0.5 $\mathrm{ml}$ ) ont été appliquées aléatoirement sur des bras opposés pendant $60 \mathrm{~min}$. L'inconfort de la canulation veineuse a été évalué sur une échelle visuelle analogique (ÉVA). Les effets secondaires ont été notés

Résultats : Soixante et un sujets ont participé à l'étude dont vingt et un ont été rejetés à cause de problèmes techniques. Quarante sujets ont complété l'étude et ont été conservés pour l'analyse des données. L'ÉVA moyenne $( \pm E ́ T)$ du LET était inférieure à celle de l'EMLA $(10.9 \pm 9.0 \mathrm{~mm}$ rs $22.7 \pm 17.1 . P<0.001)$. L'érythème secondaire à la vasodilatation était plus fréquent dans le groupe LET que dans le groupe EMLA (33 vs 3. $P<0,001)$. Un des sujets considéré comme atopique a présenté de l'érythème au site d'application du LET. Conclusion : La tétracaïne encapsulée dans les liposomes peut procurer une anesthésie topique plus efficace que l'EMLA pour la canulation veineuse après $60 \mathrm{~min}$ d'application. Des évaluations cliniques sont nécessarres pour déterminer l'efficacité et l'innocuité du LET pour l'anesthésie topique pendant des manipulations percutanées diverses chez d'autres groupes de patients.

From the Departments of Anaesthesia and Pharmacology, and College of Pharmacy, ${ }^{*}$ Dalhousie University, Halifax, Nova Scotia, Canada Address correspondence to: Dr. Orlando Hung, Department of Anacsthesia, Queen Elizabeth II Health Sciences Centre, Victoria

General Hospital, Halifax, Nova Scotia, Canada B3H 2Y9. Phone: 902-473-7767; Fax: 902-423-9454; E-mail address: hungorla@is.dal.ca Funding for this study was provided in part by Medical Research Council of Canada and Paincare Associates Canada Inc. Acceted for publication April 19, 1997. 
$\mathrm{P}$ ATIENTS undergoing venipuncture or intravenous catheterization often experience pain which makes minor invasive procedures difficult for both the patient and the health care personnel. The eutectic mixture of local anaesthetics (EMLA ${ }^{\otimes}$, Astra Pharma Inc., Mississauga, Ont) with lidocaine $2.5 \%$ and prilocaine $2.5 \%$ has been shown to decrease the discomfort of such procedures, particularly in paediatric patients. ${ }^{1}$ Although it is considered to be effective, the onset of anaesthesia is slow. The depth of penetration and degree of topical anaesthesia attained following EMLA application depends on the duration of the application. A recent study has shown that following a 60 min EMLA application to the skin, only $45 \%$ of the subjects demonstrated complete loss of pin prick sensation at the site. ${ }^{2}$ Topical anaesthesia for more invasive procedures such as splitthickness skin graft harvesting may require up to two hours EMLA application. ${ }^{3}$ This delay in onset of topical anaesthesia is inconvenient as well as impractical in some clinical settings.

Liposomes are microscopic vesicles composed of an aqueous compartment surrounded by a phospholipid bilayer which acts as a permeable barrier to entrap either hydrophilic or lipophilic drug molecules. ${ }^{4}$ Liposomes have been used as intravenous drug carrier systems in enzyme replacement therapy, ${ }^{5}$ antifungal therapy, ${ }^{6}$ and chemotherapy. ${ }^{7}$ Apart from being effective drug carriers, liposomes can also enhance drug delivery to the dermis by increasing the rate of dermal penetration of drugs. $^{8}$

A recent study demonstrated that tetracaine has faster dermal penetration than other commonly used local anaesthetics, including lidocaine and prilocaine. ${ }^{9}$ This suggests that tetracaine may provide a more rapid onset of topical anaesthesia. Thus, topically applied liposome-encapsulated tetracaine may be a more efficient drug delivery system to provide topical anaesthesia for invasive surgical procedures and intravenous catheterization. ${ }^{10}$

The goal of this study was to compare the effectiveness of a 60 min application of liposomal-encapsulated tetracaine (LET) and EMLA in providing percutaneous local anaesthesia for intravenous catheterization in healthy volunteers.

\section{Methods}

\section{Preparation of the study formulations}

The encapsulation procedure of tetracaine was based on an established and patented method ${ }^{\mathrm{A}}$ under Good Manufacturing Practice (GMP) conditions. All components of the products were of pharmacopoeia grade.
These included phospholipon 90-G, cholesterol, USP, and sterile saline solution. All the preparations were freshly made for the study, with no other additives such as preservatives, antioxidants, and other auxiliary agents. The LET formulation consisted of tetracaine $5 \%$ base, soya phosphatidylcholine 7\% (NC-95-H, American Lecithin Co., Atlanta, Georgia), stearic acid 0.7\% USP (Fisher Scientific Co.), and cholesterol 0.7\% (Sigma Chemical Co.).

Both local anaesthetic formulations, EMLA ${ }^{\boxplus}$ (Astra Pharma Inc., Mississauga, Ontario) and LET were dispensed into $1.5 \mathrm{ml}$ ampoules (Eppendorf tubes) and coded as either cream " $\mathrm{A}$ " or cream " $\mathrm{B}$ " by one of the investigators $(M M)$. This investigator was not involved with the clinical study and did not have any contact with study subjects. The investigators were unblinded only at the end of the study.

\section{Collection of data}

This double-blind randomized clinical trial was approved by the institutional review board and written informed consent was obtained from all participants. Healthy volunteers $>18$ yr were recruited for the study. Subjects who were taking concurrent analgesics or with a history of allergies to local anaesthetics were excluded from the study.

While sitting in a comfortable chair, a tourniquet was applied, and the antecubital fossae of both arms of the subject were examined to identify appropriate veins for catheterization. $\mathrm{A} 4 \mathrm{~cm} \times 4 \mathrm{~cm}$ area was outlined on each antecubital fossa with a marker. Following thorough cleaning of the marked areas with alcohol swabs, $0.5 \mathrm{ml}$ of either Cream A or Cream B was randomly (coin toss) applied to the marked areas. To minimize the bias of learning during catheterization, the order of application of the study creams was also randomized. The study cream was spread out evenly with a tongue depressor on the outlined area and covered with an occlusive dressing (Tegaderm ${ }^{\mathrm{TM}}$ $3 \mathrm{M}$, London, Ontario). The time of application of each cream was recorded. After $60 \mathrm{~min}$, excess cream was removed and the outlined skin area was inspected for erythema, or urticaria. The presence or absence of itching in the area was also noted. The skin was again cleaned with an alcohol swab and a \#18 gauge Jelco (Critikon, Tampa, Florida) iv catheter was inserted into a vein in the outlined area. The time required for $i v$ insertion was recorded. The discomfort caused by the $i p$ insertion was immediately assessed using a 10 point visual analog pain scale (VAS). The procedure was repeated for the other study cream for the opposite arm. The side effects, time for the iv catheter insertion, and VAS were recorded. 


\section{Data analysis}

To minimize the variability of the painful stimuli (ip insertion), only successful $i v$ catheterizations in which the $i v$ catheter was advanced completely into the vein on the first attempt in both arms were included for data analysis. This was done to prevent masking of the true topical anaesthetic effect of the preparations by pain caused by "traumatic" catheterization into the subcutaneous tissues adjacent to a vein.

All data were expressed as mean $( \pm S D)$ unless otherwise specified. Ordinal data were analyzed using the Wilcoxon Signed Rank Test. Nominal data were analyzed using chi-square contingency table. Continuous data were analyzed using Student's paired t test. A $P$ $<0.05$ was considered statistically significant.

\section{Results}

Sixty-one subjects (28 female and 33 male) were recruited to the study. Twenty-one were excluded because of technical difficulties in identifying veins at the antecubital fossae with multiple needle punctures (five subjects), failure to insert the iv catheter into the vein at one or both of study sites (fifteen subjects), or concurrently using an analgesic (one subject). Forty subjects ( 12 female and 28 male) completed the study and were included in the data analysis. The mean $\pm \mathrm{SD}$ age, weight, and height of the 40 subjects were 27.8 $\pm 6.0 \mathrm{yr}, 172.0 \pm 10.4 \mathrm{~cm}$, and $73 \pm 11.2 \mathrm{~kg}$ respectively. There were no differences between the duration of application $(61.5 \pm 3.3 \mathrm{~min}$ for EMLA ps $61.6 \pm 3.7$ min for LET), or the time required for iv catheter insertion ( $16.4 \pm 19.4 \mathrm{sec}$ for EMLA vs $12.6 \pm 7.7 \mathrm{sec}$ for LET). The VAS scores were lower for LET than for EMLA (11.0 $\pm 9.0 \mathrm{~mm}$ for LET vs $22.7 \pm 17.1$ $\mathrm{mm}$ for EMLA, $P<0.001$ ). (Table I)

No serious complications occurred during the study. One patient, with a history of atopy, in the LET group developed hives at the site of cream application. Minor skin changes, such as erythema, occurred more frequently in the LET group than in the EMLA group ( 33 for LET $v s 3$ for EMLA, $P<0.001$ ). (Table I) Similarly,

TABLE I The results and side effects following $60 \mathrm{~min}$ application of the eutectic mixture of local anaesthetic (EMLA) and liposome-encapsulated tetracaine (LET) in healthy volunteers.

\begin{tabular}{lll}
\hline Group & EMLA & LET \\
Number & 40 & 40 \\
Duration of application (min) & $61.5 \pm 3.6$ & $61.6 \pm 3.8^{\star}$ \\
Time to $i v$ insertion (sec) & $16.5 \pm 19.4$ & $12.7 \pm 7.7^{\star}$ \\
VAS (mm) & $22.7 \pm 17.1$ & $11.0 \pm 9.0^{\star \star *}$ \\
Erythema & 3 & $33^{\star \star \star}$ \\
Rash & 0 & $1^{*}$ \\
Itch & 1 & $9^{* *}$ \\
\hline$* P>0.05 * * P<0.01 * * * P<0.001$ &
\end{tabular}

there were more subjects who reported itching in the LET group than in EMLA group (9 vs $1, P<0.01$ ).

\section{Discussion}

Our data demonstrate that topical application of liposome-encapsulated tetracaine $5 \%$ can provide more effective topical anaesthesia than EMLA for invasive procedures, such as intravenous catheter insertion following a $60 \mathrm{~min}$ application. However, there were more minor side effects such as erythema and itching at the site of application with LET than with EMLA.

There are several potential advantages of using liposome-encapsulated tetracaine cream to provide topical anaesthesia compared with EMLA: 1.Tetracaine has been shown to have the most rapid onset of analgesia compared with other commonly used local anaesthetics, such as lidocaine, bupivacaine, and mepivacaine; 92 . Although the exact mechanism is not fully understood, liposomal vesicles have been shown to enhance drug entry into intact skin, ${ }^{8,11,12}$ potentially shortening the duration of application required to achieve topical anaesthesia; 3 . Liposome-encapsulation of tetracaine has been demonstrated to prolong the analgesic effect, ${ }^{10,13}$ possibly due to the delay in clearance of the drug from the site of application; 4. Liposome-encapsulation can delay systemic absorption of tetracaine from the tissues, resulting in a lower plasma concentration of tetracaine and a lower risk of systemic toxicity; ${ }^{14}$ 5. Prilocaine, a major ingredient of EMLA, has been shown to cause methaemoglobinaemia, particularly in infants. ${ }^{15,16}$ Liposome-encapsulated tetracaine may be a valuable substitute for EMLA in providing topical anaesthesia for minor surgical procedures, such as circumcision, in small infants to minimize the risk of developing methaemoglobinaemia.

Tetracaine is an aminoester local anaesthetic which is hydrolysed rapidly in plasma by the cholinesterase enzymes and thus has a short plasma elimination halflife. One of the metabolites of tetracaine, paraaminobenzoic acid (PABA), has been reported to cause an allergic-type reaction in a small percentage of patients. ${ }^{17}$ Although rare, allergic reactions such as contact dermatitis, have also been reported with amide local anaesthetics, including EMLA (prilocaine) and bupivacaine. ${ }^{18,19}$ One subject with a history of atopy developed hives at the site of LET cream application. It is unknown if there is an association of allergic contact dermatitis and tetracaine in patients with a history of atopy. Perhaps topical application of ester type of local anaesthetics, such as tetracaine, should be used with caution in this patient population.

Erythema developed at the site of LET application in more than $80 \%$ of the subjects. As previously 
reported, this is most likely due to the vasodilatory effect of tetracaine. ${ }^{20}$ Doyle $e t a l$. reported that $44 \%$ of patients developed erythema following topical application of amethocaine (tetracaine). Since iv catheterization was easier following the application of tetracaine, they suggested that vasodilatory effect of tetracaine may be beneficial for iv catheterization,. Although there was no objective evidence of such an advantage in our study, the mean time to insert an intravenous catheter was shorter for the LET group than for the EMLA group $(12.6 \pm 7.7 \mathrm{sec} v s 16.4 \pm 19.4 \mathrm{sec})$. It is also unknown if vasodilatation caused by tetracaine enhanced the penetration of LET through the skin, thus shortening the onset time for topical anaesthesia. In contrast, EMLA has been demonstrated to cause a biphasic cutaneous vascular response with an initial peak vasoconstriction effect at $1.5 \mathrm{hr}$ following the topical application, followed by a late vasodilatation three hours after the application. ${ }^{21}$ Perhaps, the initial vasoconstriction may, in part, explain the delay in onset of local anaesthetic effect of EMLA.

Although the manufacturer suggests $2.5 \mathrm{~g}$ (or 2.5 $\mathrm{ml})^{\mathrm{B}}$ EMLA to achieve topical anaesthesia for iv catheter insertion, we felt this amount was excessive and unnecessary. Therefore, a smaller dose $(0.5 \mathrm{ml})$ was used for both LET and EMLA in this study. Our data showed that the mean VAS for iv catherization was $22 \mathrm{~mm}$ following a $60 \mathrm{~min}$ application of $0.5 \mathrm{ml}$ EMLA. Comparable VAS scores $(19 \mathrm{~mm}$ and 13.5 $\mathrm{mm}$ following 30 and $60 \mathrm{~min}$ application) were reported by Molodecka et al using 2.5 g EMLA. ${ }^{22}$ In the same study, the authors demonstrated that one gram amethocaine $5 \%$ cream provided effective topical anaesthesia for iv catheterization following $30 \mathrm{~min}$ application. Furthermore, Planas et al. found that 0.5 $\mathrm{ml}$ liposomal-encapsulated tetracaine $4 \%$ applied over a $9 \mathrm{~cm}^{2}$ area provided good insensitivity to pinprick stimuli after 25 min application. ${ }^{13}$ These findings suggest that $0.5 \mathrm{ml}$ of these creams can provide effective topical anaesthesia for $i v$ catheterization.

Since the discovery of liposomes in 1965 by Bangham, ${ }^{4}$ the technology to manufacture liposomal drug delivery systems has become mature and well established. Liposomes are biocompatible, biodegradable, and nontoxic, making them suitable as drug carriers. ${ }^{23}$ Many dermatological liposomal preparations are commercially available. Although tetracaine is generically available and the production of liposomeencapsulated tetracaine is relatively inexpensive, the sterility, stability and clinical applications of the liposomal tetracaine preparation remain to be determined.

In conclusion, our data show that $60 \mathrm{~min}$ application of liposome-encapsulated tetracaine provide superior topical anaesthesia to intact skin for ip catheterization than does EMLA. Although the rapid onset of topical anaesthesia may provide a faster turnover for minor out-patient invasive percutaneous procedures and better post-operative analgesia following minor surgical procedures, clinical evaluations are necessary to define its efficacy and safety in providing topical anaesthesia in different patient populations.

\section{References}

1 Nilsson A, Boman I, Wallin B, Rotstein A. The EMLA patch - a new type of local anaesthetic application for dermal analgesia in children. Anaesthesia 1994; 49 : 70-2.

2 McCafferty $D F$, Woolfson $A D$, Boston V. In vivo assessment of percutaneous local anaesthetic preparations. $\mathrm{Br}$ J Anaesth 1989; 62: 17-21.

3 Bjerring P, Arendt-Nielsen L. Depth and duration of skin analgesia to needle insertion after topical application of EMLA cream. Br J Anaesth 1990; 64: 173-7.

4 Bangham AD, Standish MM, Watkins JC. Diffusion of univalent ions across the lamellae of swollen phospholipids. J Mol Biol 1965; 13: 238-52.

5 Belchetz PE, Braidman IP, Crawley JCW, Gregoriadis G.Treatment of Gaucher's disease with liposomeentrapped glucocerebroside: ß-glucosidase. Lancet 1977; ii: 116-7.

6 Lopez-Berestein G, Fainstein V, Hopfer R, et al. Liposomal amphotericin $B$ for the treatment of systemic fungal infections in patients with cancer: a preliminary study. J Infect Dis $1985 ; 151: 704-9$.

7 Sculier JP, Coune A, Brassine $C$, et al. Intravenous infusion of high doses of liposomes containing NSC 251635, a water-insoluble cytostatic agent. A pilot study with pharmacokinetic data. J Clin Oncol 1986; 4: 789-97.

8 Foldvari $M$, Gesztes $A$, Mezei $M$. Dermal drug delivery by liposome encapsulation: clinical and electron microscopic studies. J Microencapsul 1990; 7: 479-89.

9 McCafferty DF, Woolfson $A D, M c$ Clelland $K H$, Boston $V$. Comparative in vivo and in vitro assessment of the percutaneous absorption of local anaesthetics. $\mathrm{Br} J$ Anaesth 1988; 60: 64-9.

10 Gesztes $A$, Mezei $M$. Topical anesthesia of the skin by liposome-encapsulated tetracaine. Anesth Analg 1988; 67: 1079-81.

11 Mezei $M$. Liposomes in the topical application of drugs: a review. In: Gregoriadis G (Ed.). Liposomes as Drug Carriers: Recent Trends and Progress. New York: John Wiley \& and Sons Ltd., 1988: 663-77.

12 Ganesan MG, Weiner ND, Flynn GL, Ho NFH. Influence of liposomal drug entrapment on percutaneous absorption. International Journal of Pharmaceutics 1984; 20: 139-54. 
13 Planas ME, Gonzalez P, Rodriguez L, Sanchez S, Cevc $G$. Noninvasive percutaneous induction of topical analgesia by a new type of drug carrier, and prolongation of local pain insensitivity by anesthetic liposomes. Anesth Analg 1992; 75: 615-21.

14 Fisher R, Murphy M, Hung O, Mezei M, Stewart R. Absorption of liposome-encapsulated tetracaine versus nonliposome-encapsulated tetracaine from open wounds in rabbits. Am J Emerg Med 1994; 12: 521-3.

15 Biscoping J, Michaelis G, Hempelmann G. Prilocaine plasma concentrations following intravenous regional anesthesia (IVRA) and their relation to methemoglobinemia. (German) Regional Anaesthesie 1988; 11 : 35-9.

16 Nilsson A, Engberg $G$, Henneberg $S$, Danielson $K, D e$ Verdier $C$ - $H$. Inverse relationship between age-dependent erythrocyte activity of methaemoglobin reductase and prilocaine-induced methaemoglobinaemia during infancy. Br J Anaesth 1990; 64: 72-6.

17 Reynolds $F$. Local anaesthetic drugs. Clinics in Anesthesiology 1984; 2: 577-603.

18 Hardwick $N$, King CM. Contact allergy to lignocaine with cross-reaction to bupivacaine. Contact Dermatitis $1994 ; 30 ; 245-6$.

19 Evers H, Von Dardel O, Jublin L, Oblsén L, Vinnars E. Dermal effects of compositions based on the eutectic mixture of lignocaine and prilocaine (EMLA). Br J Anaesth 1985; 57: 997-1005.

20 Doyle E, Freeman J, Im NT, Morton NS. An evaluation of a new self-adhesive patch preparation of amethocaine for topical anaesthesia prior to venous cannulation in children. Anaesthesia 1993; 48: 1050-2.

21 Bjerring $P$, Andersen PH, Arendt-Nielsen L. Vascular response of human skin after analgesia with EMLA cream. Br J Anaesth 1989; 63: 655-60.

22 Molodecka J, Stenhouse C, Jones JM, Tomlinson $A$. Comparison of percutaneous anaesthesia for venous cannulation after topical application of either amethocaine or EMLA cream. Br J Anaesth 1994; 72: 174-6.

23 Shek PN, Suntres ZE,Brooks JI. Liposomes in pulmonary applications: physiochemical considerations, pulmonary distribution and antioxidane delivery. $\mathrm{J}$ Drug Target 1994; $2: 431-42$.

\section{Footnotes}

A Mezei M, Nugent FI: Method of encapsulating biologically active materials in multilamellar vehicles (MLV). U.S. Patent No. 4,485,054, 1984, Canadian Patent No. 1205383, 1986.

${ }^{\text {B }}$ Specific gravity of EMLA is 1 . (Physicians' Desk Reference, $48^{\text {th }}$ Ed, Medical Economics Company Inc., Oradell, NJ, 1996, pp544.) 